2016 Modular and Offsite Construction (MOC) Summit

Edmonton, Alberta, Canada, September 29 - October 01, 2016

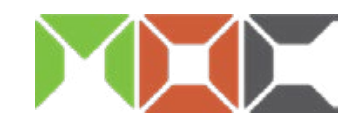

\title{
3D Motion-based Ergonomic and Body Posture Analysis in Construction
}

\author{
Xinming $\mathrm{LI}^{1 *}$, SangHyeok HAN ${ }^{2}$, Mustafa GÜL ${ }^{3}$ and Mohamed AL-HUSSEIN ${ }^{4}$ \\ ${ }^{1}$ PhD Candidate, Department of Civil and Environmental Engineering, University of Alberta \\ ${ }^{2}$ Assistant Professor, Department of Building, Civil and Environmental Engineering, Concordia \\ University \\ ${ }^{3}$ Assistant Professor, Department of Civil and Environmental Engineering, University of Alberta \\ ${ }^{4}$ Professor, Department of Civil and Environmental Engineering, University of Alberta \\ "Corresponding author's e-mail: xinming1@ualberta.ca
}

\begin{abstract}
The construction manufacturing industry in North America has a disproportionately high number of lost-time injuries due to the higher physical demand of labour-intensive tasks. It is thus essential to investigate the physical demands of body movement in the workplace in order to identify worker exposure to ergonomic risk. This paper presents a methodology for converting video-captured body movements in an actual manufacturing plant into 3D virtual animations for ergonomic risk analysis. Through 3D virtual animation, dynamic human body data can be obtained (such as joint angles) for body posture risk assessment analysis using existing risk assessment algorithms. The presented framework enables body motion risk identification by detecting awkward body postures, evaluating handled force/load and frequency that cause ergonomic risk during body movements of workers. The capability of the 3D modelling can be extended to support the re-design of the workplace and optimization of human body movement accordingly in order to mitigate ergonomic risk. The methodology is implemented in a case study in order to analyze operational tasks in manufacturing plants. Modified work recommendations are expected as a result of this systematic 3D ergonomic analysis which will further reduce potential injuries and workers' compensation insurance costs in the long term.
\end{abstract}

\section{KEYWORDS}

Ergonomic Analysis, 3D Visualization, Risk Assessment, Modified Work, Physical Demand Analysis

\section{INTRODUCTION}

The workers in a construction company are exposed to tasks with much higher physical demand, such as overexertion, repetitive motion, and awkward body posture, than those to which workers in other industries are exposed, thereby resulting in work-related musculoskeletal disorders (WMSDs) (Wang et al., 2015; OSACH, 2010). Schneider (2001) reports that construction workers are at risk of developing WMSDs, which serve to reduce productivity and increase construction costs. These risks arise from the fact that many workers in this sector are involved in various construction activities such as cleaning, assembling, preparing the construction site, loading and unloading building material, operating power tools, and operating machinery. To 
some extent, ergonomic analysis thus facilitates increased productivity due to the reduction of inefficient and non-productive motions. Fatigue and lack of motivation are other factors related to ergonomics that could result in a loss of productivity. The improvement of physical and psychological conditions of the workstation can thus increase worker productivity (Elola et al., 1996). The partial ergonomic risk analysis in construction activities has been implemented by existing ergonomic analysis models such as Ovako Work posture Analysing System (OWAS) (Karhu et al., 1997), Rapid Entire Body Assessment (REBA) (Hignett and McAtamney, 2000; Janowitz et al., 2006), and Rapid Upper Limb Assessment (RULA) (McAtamney and Corlett, 1993). Inyang and Al-Hussein (2011) propose a comprehensive framework for evaluating and quantifying ergonomic effects on each body part while the worker is performing construction activities. Even though workers are greatly affected by their workplaces, these studies have not considered environmental factors as a means to assist in designing productive and safe operations. From a lean perspective, the workplace must be organized and standardized to achieve higher productivity by reducing the number of accidents and errors that occur (Dennis, 2002). The existing methods for assessing safety risk can provide a priori risk estimates and can measure the frequency of unsafe behaviours or conditions, but do not provide a way to assess the potential for accidents based on the actual execution of the operation (Mitropoulos et al., 2009). Thus, it is critical to discover a method to proactively identify and mitigate WMSD risk. The research presented in this paper thus aims to develop a framework to identify ergonomic risks, even in the design phase of manufacturing plants, in order to reduce potential work-related injuries and claims.

Physical Demand Analysis (PDA) is a systematic method which allows the industry to be proactive rather than responding after a worker suffers an injury that requires them to take time off work (WCB, 2009a). PDA serves to document the strength demand, motion frequency, sensory demand, and environmental demand of a task (IAPA, 2009; Li et al., 2015). For data collection in ergonomic analysis, David (2005) identifies three methods: (1) self-reports; (2) physiological measurements; (3) observational method. Using the observational method, PDA and ergonomic posture assessment have been developed for traumatic injury incidents such as falls and being struck by objects. However, these methods can be time-consuming and errorprone since the required information, such as joint angles of a body, must be collected accurately and efficiently in order to support analysis of the potential risks of tasks and workers.

Among the various approaches for human body motion data collection, 3D visualization allows its users to imitate and simulate an operational task on the computer screen, which is less timeconsuming, and avoids costly on-site devices, human error, and technique issues. It can also proactively visualize a proposed design prior to implementation in the real world. Many researchers (Juan et al., 2007; Al-Hussein et al., 2005; Stub-French et al., 2008; Han et al., 2014) have demonstrated that $3 \mathrm{D}$ visualization is an effective tool for various purposes such as identifying operation of heavy facilities, space conflict, site layout, and construction sequences. Feyen et al. (2000) develop a 3D static strength prediction program using the AutoCAD interface as a proactive biomechanical risk analysis tool based on postural and dynamic load analysis functionalities and methods for preventing injury risks at the earliest design stages. Other risk assessment tools, such as REBA and RULA, also require detailed physical data and joint angle for the purpose of completing body posture analysis. These risk assessment tools have not been fully implemented in construction cases due to these limitations with regard to physical measurements. Joint angle and body posture can be obtained not only by direct measurement, but also by indirect measurement (Alwasel et al., 2011; Ray and Teizer, 2012; Han and Lee, 2013). 
The 3D visualization allows its users to experiment with and simulate a proposed design on a computer screen in order to avoid costly on-site devices, human error, technique issues, and time-consumption prior to implementation in the real world.

However, previous studies have used only some aspects of 3D visualization functionalities for their respective objectives. These studies do not provide detailed or complete descriptions of a project, such as the worker's motions and repetitions in regular construction operations or material handling. In order to overcome this limitation, Golabchi et al. (2015) propose a framework for an automated biomechanical simulation approach to ergonomic job analysis for workplace design using 3D visualization. This research extends the range of applicability of 3D visualization as a support tool in order to collect all engineering information for ergonomic posture analysis in a production line, as well as an educational and training tool for junior workers. The utilization of 3D automation, it should be noted, is a strong support for motion data collection, enabling animation of the motion in order to simulate reality through careful editing and drawings. Moreover, 3D visualization enables the user to adjust and customize the human model and workplace design, thereby providing easy access for researchers to conduct risk assessment comparison for diverse alternatives, including differences in the design of the workstation and differences in height range of the human body. Apparently, 3D animation, by circumventing the ethical issues associated with real-world construction, allows researchers to assess the motion even in the early design stage of a project or when maximum human body capacity is required to complete the work. The results can be used to assist health and safety personnel in identifying work-related risks and recommending proper working postures and body motions for operational tasks. This paper thus introduces a method which designs physical demand analysis for modular construction activities with the dynamic, graphical 3D visualization as an observation and support tool for analyzing the potential ergonomic risks and accidents associated with construction activities. Thus, the output can help construction planners to eliminate or mitigate potential risk factors in a proposed design.

\section{D ERGONOMIC ANALYSIS METHOD}

In general, six phases are included in this framework, as indicated in Figure 1. The inputs of this framework include a summary of current PDA form contents, worker information, factory layout, and current task maneuvers, workstation design and working schedule, etc.

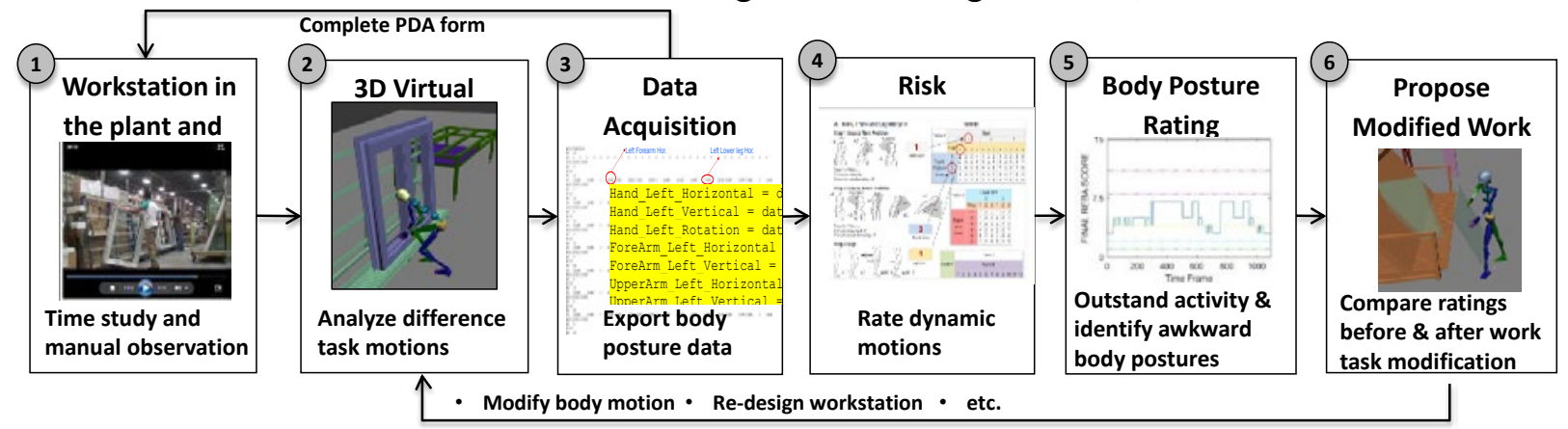

Figure 1. Overall methodology and framework of the proposed ergonomic risk assessment

The framework begins with phase one, where a manual plant observation and time study are conducted in order to obtain a brief overview of the operation process and physical demand of operational tasks. While performing phase one, physical demand and productivity analysis data can be obtained; the body posture is recorded by a 60-minute time study (Li et al., 2015), and 
strength, sensory, and environmental demands are also measured. All the information will be summarized in a preliminary PDA form by the end of phase one.

In phase two, a 3D virtual animation model for activities in the production line is created, based on previous plant observation and preliminary PDA. 3ds Max (Autodesk, 2016) is chosen to create human body working motion animations. Based on the plant layout and equipment/machine measurement in phase one, the first step is to draw the workstation and plant layout in the 3D model. Following this, the same motion as performed by the worker in the video recording is animated. The animation is capable of representing awkward body postures, such as bend forward, reach above shoulder, kneel, squat, or crouch, when the human body model is performing a task. Of course, the movement from one human body model animation cannot represent all human movements for all workers; different workers may have alternative working behaviours for handling heavy materials and completing operational tasks. The strength of this framework also stems from the fact that $3 \mathrm{D}$ visualization enables the animation and simulation of different methods of completing one task and comparing the results. In this study, the goal is to compare the body posture risk assessment of diverse methods of completing one task and to propose the optimal method. To make the 3D human body motion modelling more realistic, several rounds of modifications may be required. Having an animation that is precise and accurate is critical because it is to be utilized for physical demand data (human body motion, force/load, etc.) extraction for phase three.

In phase three, joint angles are calculated by assessing the coordination of related bones in the human skeleton model; force and load on the body part are estimated. Data acquisition in this phase primarily consists of human body joint angles (e.g., flexion angle, rotation angle, bending angle). To obtain the body posture joint angles for various body postures and movements, MAXScript, which is the built-in language in 3ds Max software (Autodesk, 2011), is used in conjunction with programming code. Referring to the joint angle calculation methodology from the "3D Static Strength Prediction Program" developed at the University of Michigan (2012), joint angles for hand, forearm, upper arm, clavicle, upper leg, lower leg, foot, head, neck, trunk, and pelvis are calculated and generated. It should be noted that left and right side, horizontal and vertical, rotation, lateral bend, and flexion are distinguished and calculated separately. A biped's skeletal structure is set based on the requirements from the calculation with one neck link, one spine link, three leg links, one finger, one finger link, one toe, and three toe links. In total 41 joint angles are obtained from this phase. By selecting the time frame of the animation and running MAXScript calculation (Figure 2a), joint angles for body parts can be captured by each frame of 3D animation in batch file (Figure 2b). The extracted data from 3D animation serves as the input for phase four, the risk assessment phase, and is also the input for an improved PDA form.

In phase four, REBA/RULA risk assessment method is utilized for rating each motion. REBA/RULA is a systematic tool, evaluating the entire body posture during the task by using the joint angles, force/load, repetition, and coupling conditions (Hignett and McAtamney, 2000; Middlesworth, 2012; McAtamney and Corlett, 1993). REBA focuses on the entire body working posture while RULA emphasizes the upper limb disorders for ergonomic identifications and designs. The rating is calculated by using MATLAB programming software to read the batch file generated from the previous phase, and is graphically plotted for each individual body part, including trunk, neck, arm, leg, and wrist, as well as for the total score of the entire motion at the respective time frame, considering force/load and activity repetitions. 
a. Obtain joint angles

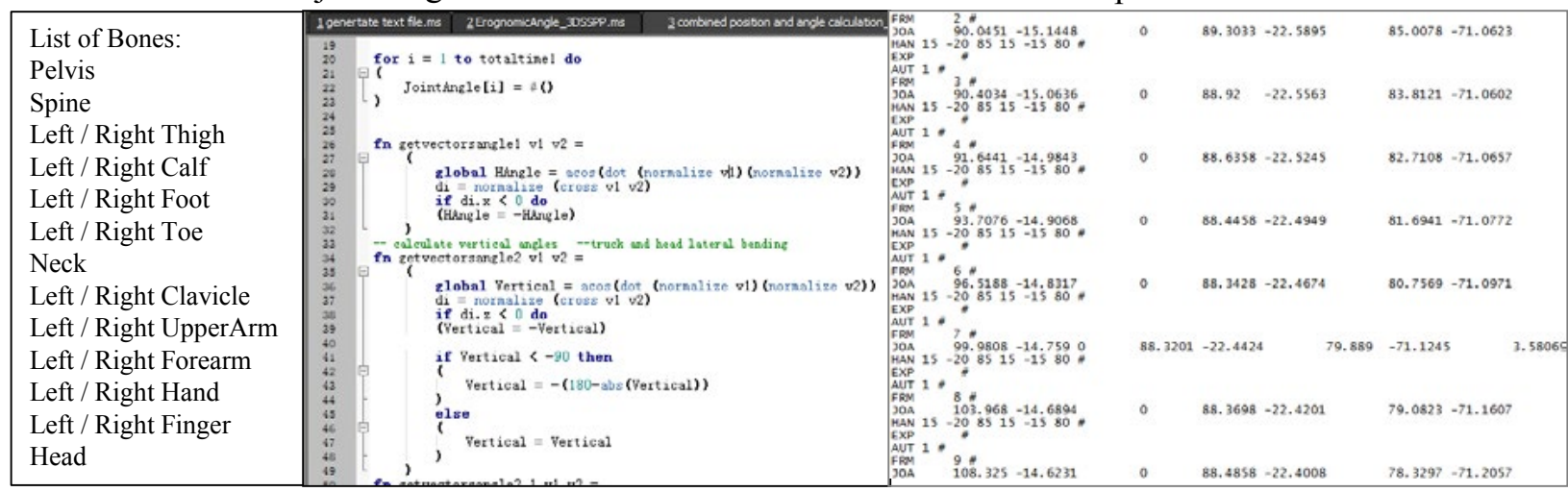

Figure 2. Example file of obtaining the joint angles and batch file generation

In phase five, the total risk rating is given in the final REBA/RULA score chart for a continuous and dynamic working operation process. Aggregating all the body posture movements, the total rating is found to fluctuate during the movement. The final REBA/RULA score considers the joint angle of each individual body part, force/load added to the body, and the frequency of the activity, among others. Five risk severity levels are categorized in the REBA methodology, while four levels are categorized in the RULA methodology. During the entire process, not all the human body motions encompass high risk. However, the high-risk motion can be identified through this rating algorithm. The peak rating and the corresponding human body motion are identified by comparing the plotted chart with the 3D animation. Moreover, risk ratings are plotted for each body part, a task which assists in providing understanding of which body parts are exposed to higher risks during the operation, as indicated in Figure 3. Proactive measures can be suggested and recommended for this motion by revising the task maneuver for the body part with high rating or modifying the task maneuver entirely, as per the next phase.

Tasks with high ergonomic risk can thus be identified and corresponding corrective measures proposed in phase six. If the overall rating is found to be unacceptable (i.e., if potential ergonomic risks exist in the current production line), then the entire process proceeds to phase six, recommending modified work to be implemented for the identified motion with high associated risk. Providing the proposed modified work and the change of task maneuvers to workers allows them to continue work with lower ergonomic risk, especially for injured workers; this method allows them to continue to add value to the company's operations. To be more specific, the modified work can be proposed as follows: (1) re-structuring of the workstation; (2) modification of production operations; (3) revision of human body motion; (4) work carried out with the assistance of other workers; and (5) staggering of the task between workers. Time frame in 3D animation can be calculated by the task duration data obtained from time study. Each time frame is equal to a certain time period while each motion (such as raising arm up, walking, etc.) takes a certain time period. The modified work must be built based on the same time frame ratio (Frame per second) to animate the motion. Thus from this method, the duration of the proposed modified work can be roughly estimated, and this estimated duration will be further implemented in the simulation model for productivity analysis. Moreover, the solutions vary from case to case, with a lower ergonomic rating expected after applying modified work by repeating phases 2-5. 


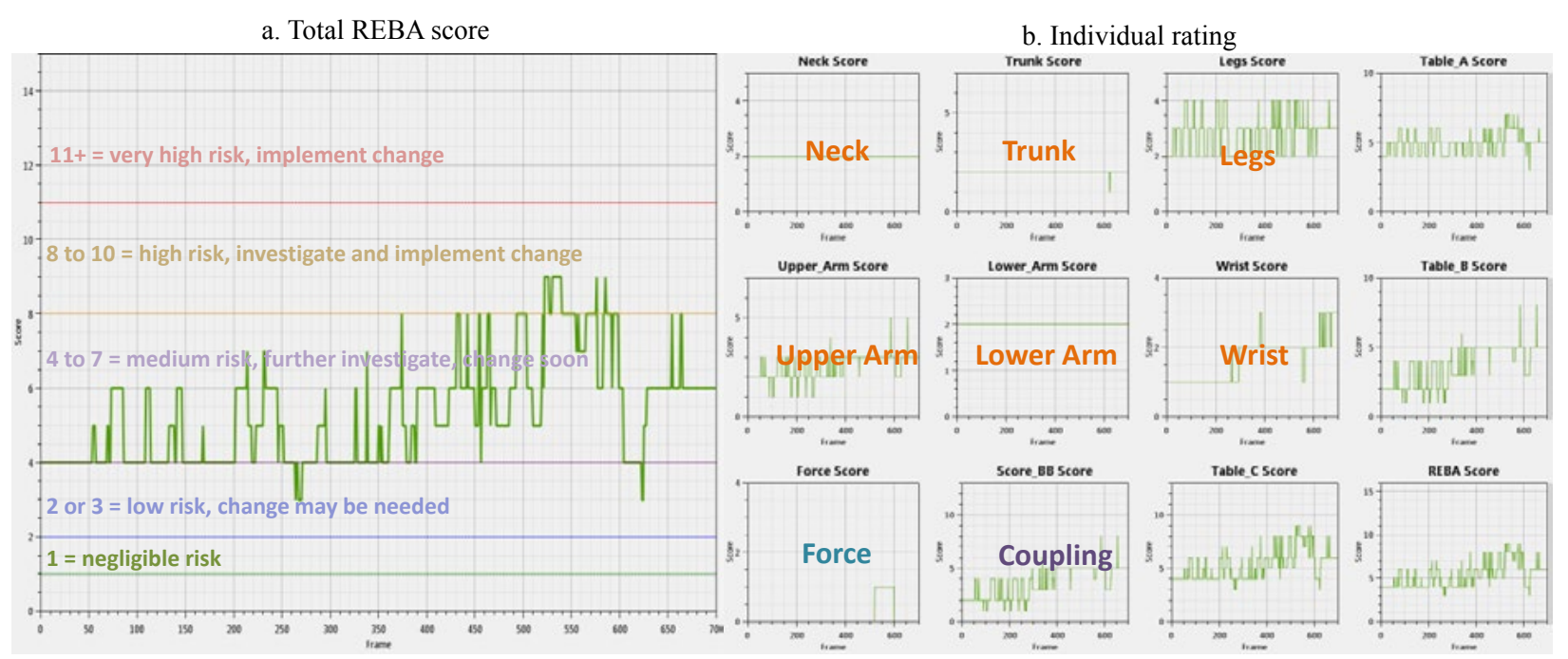

Figure 3. Risk assessment sample final REBA score and detailed rating for each body part

It should be noted that the research presented in this paper must follow ergonomic guidelines and may be limited by certain criteria, such as the risk factors and constraints from the plant layout and the 3D model. The output of this framework is an improved systematic PDA, overall task maneuver analysis, and ergonomic risk summary, from which modified work can be proposed. Not only is a significant reduction of ergonomic risks expected, but improved productivity of the line is also within the scope of work. Eventually, injury reduction and an analysis of its effect on cost will be conducted.

\section{IMPLEMENTATION}

The window glazing station is selected as a case study in this section. The window must be glazed on a tilted supportive shelf equipped with a supporting roller on the bottom. A series of motions, listed in Figure 4.a, is captured during this case study. This motion series begins with walking to pick up a $20 \mathrm{lbs}$ window frame, followed by dragging the window frame toward the workstation, tilting one side of the window frame onto the workstation, lifting the other side of the window frame onto the workstation, and, finally, positioning the window frame for window glazing operation. For the window glazing, the worker must also carry the heavy window glass to the workstation and insert it into the window frame followed by the corresponding window glazing tasks. REBA risk assessment method is utilized in this methodology to rate each motion. The rating is calculated through MATLAB programming software and is graphically plotted for the total score of the entire motion (Figure 4.b), as well as for each individual body part, including trunk, neck, arm, leg, and wrist, at their respective time frames.

During the tested operation, different body parts receive various ratings since the human model assumes different body postures in order to complete the task of placing a window on the rack. The final REBA score considers the joint angle of each individual body part, the force/load added to the body, and the frequency of the activity. The peak is located between the 500 to 600 time frames with a total rating around 8 , which is considered a medium to high risk level, thus indicating that this task maneuver requires further investigation. With a proper tool or equipment to support this motion, the worker might be exposed to lower ergonomic risks. The next steps are to design for a supporting tool and to animate the motion in the design phase before making any 
investment in practices. The assessment model is still under investigation toward higher accuracy and flexibility.

a. List of motions

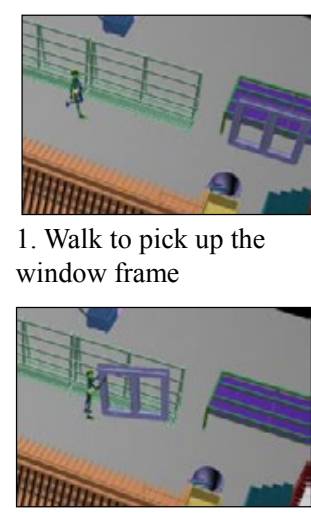

4. Tilt one side of the window frame to the workstation

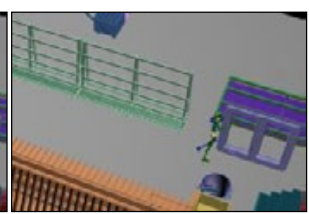

2. Drag the window

frame

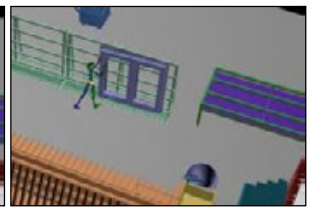

5. Lift the other side of the window frame to the frame workstation

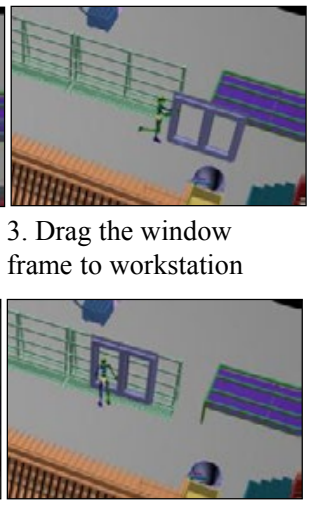

6. Posit the window b. Final REBA score

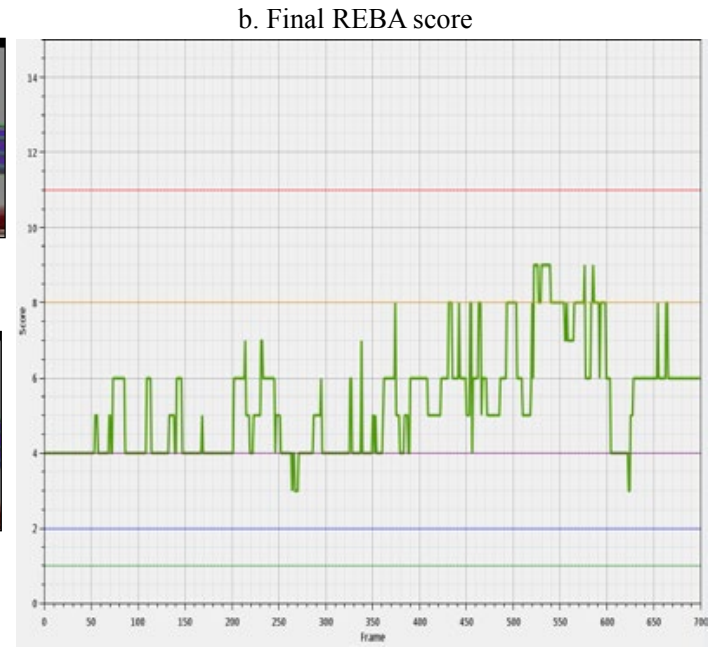

Figure 4. List of motions for a case study of placing a window on the workstation and its REBA score

\section{CONCLUSION}

This research proposes a framework for using 3D dynamic visualization to simulate the operation motion and to analyze the ergonomic risks of manufacturing construction activities. It considers the physical information and body posture of the human body, force/load, working environment, and frequency. Through brief plant observation, this method is able to identify unforeseen high-risk motions and to propose alternative operation movements in order to complete the task. This methodology eliminates the technical, ethical, and cost issues that would be at play when using other invasive and non-invasive ergonomic analysis methods. Apparently, at the beginning of 3D modelling, without any existing 3D component library to support, it is time consuming to establish all 3D components from sketch up. Fortunately, 3ds Max has massive models in existing library to support this framework and build up animations to animate and imitate the working motion in the factory. The use of 3D modelling to animate the task motions in this framework offers the benefits of (1) being capable of obtaining any dynamic human body posture data; (2) being flexible to conduct data post processing; (3) being applicable in the design phase of the workstation, such that the actual work can be carried out within safe working conditions; (4) being able to provide visualization of existing workstations and any changes made to the plant; and (5) the ability to proactively test any changes made to the plant workstation. The ultimate goal of this research is to achieve overall risk reduction in the analyzed workstations. After implementing the proposed modified work in the model, the resulting ergonomic risk rating of the production line can be expected to be lower than before.

\section{ACKNOWLEDGEMENTS}

This study is funded by the Natural Sciences and Engineering Research Council of Canada (NSERC) Industrial Research Chair (IRC) in the Industrialization of Building Construction. The authors would also like to acknowledge the support from their industry partner, All Weather Windows Ltd. 


\section{REFERENCES}

Al-Hussein, M., Niaz, M.A., Yu, H., and Kim, H. (2005). "Integrating 3D visualization and simulation for tower crane operations on construction site." Automation in Construction, 15(5), 554-562.

Alwasel, A., Elrayes, K., Abdel-Rahman, E. M., and Haas, C. T. (2011). "Sensing construction work-related musculoskeletal disorders (WMSDs)." Proceedings, International Association for Automation and Robotics in Construction (IAARC), London, U.K., pp. 164-169.

Autodesk Inc. (2016). "Create amazing worlds in 3ds Max." Retrieved from $<$ http://www.autodesk.com/products/3ds-max/overview-dts?s_tnt=69291:1:0>

Autodesk Inc. (2011). "MAXScript Introduction" Retrieved from $<$ http://docs.autodesk.com/3DSMAX/14/ENU/MAXScript\%20Help\%202012/>

David, G. C. (2005). "Ergonomic methods for assessing exposure to risk factors for work-related musculoskeletal disorders." Occupational Medicine, 55(3), 190-199.

Dennis, P. (2002). Lean Production Simplified, Second Edition, Productivity Press, New York.

Elola, L. N., Clara, A., and Tejedor, P. (1996). "New method of evaluating physical demand at work areas." Science, 16, 595-599.

Feyen, R., Liu, Y., Chaffin, D., Jimmerson, G., and Joseph, B. (2000). "Computer-aided ergonomics: A case study of incorporating ergonomics analyses into workplace design." Applied Ergonomics, 31(3), 291-300.

Golabchi, A., Han, S., Seo, J., Han, S., Lee, S., and Al-Hussein, M. (2015). "An automated biomechanical simulation approach to ergonomic job analysis for workplace design." Journal of Construction Engineering and Management, 141(8), 04015020.

Han, S. and Lee, S. (2013). "A vision-based motion capture and recognition framework for behavior-based safety management." Automation in Construction, 35, 131-141.

Hignett, S. and McAtamney, L. (2000). "Rapid Entire Body Assessment (REBA)." Applied Ergonomics, 31(2000), 201-205.

Han, S.H., Hasan, S., Bouferguene, A., Al-Hussein, M., and Kosa, J. (2014). "Utilization of 3D visualization of mobile crane operations for modular construction on-site assembly." Journal of Management in Engineering, 31(5), 04014080.

Industrial Accident Prevention Association (2009). "Performing a Physical Demands Analysis Instructions on How to Use the Physical Demands Analysis (PDA) Form." < http://www.iapa.ca/main/documents/pdf/freedownloads pda intro.pdf $>$ (Jul., 2016)

Inyang, N. and Mohamed Al-Hussein. (2011). "Ergonomic hazard quantification and rating of residential construction tasks." Proceedings, CSCE Annual Conference, Ottawa, ON, Canada, Jun. 14-17.

Manrique, J.D., Al-Hussein, M., Telyas, A., and Funston, G. (2007). "Constructing a complex precast tilt-up panel structure utilizing an optimization model, 3D CAD, and animation." Journal of Construction Engineering and Management, 133(3), 199-207.

Karhu, O., Kansi, P., and Kuorinka, I. (1997). "Correcting working postures in industry: A practical method for analysis." Applied Ergonomics, 8, 199-201.

Li, X., Fan, G., Abudan, A., Sukkarieh, M., Inyang, N., Gül, M., El-Rich, M., and Al-Hussein, M. (2015). "Ergonomics and physical demand analysis in a construction manufacturing facility." Proceedings, 5th International/11th Construction Specialty Conference, Vancouver, BC, Canada, Jun. 8-10.

McAtamney, L., and Corlett, E. N. (1993). "RULA: A survey method for investigation of work related upper limb disorders." Applied Ergonomics, 24(2), 91-99. 
Middlesworth, M. (2012). "A step-by-step guide: Rapid Entire Body Assessment (REBA)". Ergonomics Plus, from <www.ergo-plus.com $>$

Mitropoulos, P., Cupido, G., and Namboodiri, M. (2009). "Cognitive approach to construction safety: Task demand-capability model." Journal of Construction Engineering and Management, 135, 881-889.

Ontario Safety Association for Community and Healthcare (2010). "Musculoskeletal disorders prevention series Part 1: MSD prevention guideline for Ontario." < http://www.osach.ca/misc_pdf > (Mar., 2015).

Ray, S. J. and Teizer, J. (2012). "Real-time construction worker posture analysis for ergonomics training." Advanced Engineering Informatics, 26(2), 439-455.

Stub-French, S., Russell, A., and Tran, N. (2008). "Linear scheduling and 4D visualization." Journal of Computing in Civil Engineering, 22(3), 192-205.

Schneider, S.P. (2001). "Musculoskeletal injuries in construction: A review of the literature." Applied Occupational and Environmental Hygiene, 16(11), 1056-1064.

University of Michigan, Center of Ergonomics (2012). "3D static strength prediction program." $<$ http://djhurij4nde4r.cloudfront.net/attachments/files/000/000/284/original/Manual_606.pdf ?1406656210> (July, 2016)

Workers' Compensation Board (2009a). "Millard health rehabilitation centre: Workshops." $<$ http://www.wcb.ab.ca/millard/workshops.asp> (Dec., 2015).

Wang, D., Dai, F., and Ning, X. (2015). "Risk assessment of work-related musculoskeletal disorders in construction: State-of-the-art review." Journal of Construction Engineering and Management, 141(6), 4015008. 